\title{
Research on Chinese Interior Art Design Style
}

\author{
Zheng Gong \\ Fujian Jiangxia University, Fuzhou, Fujian, 350001
}

Keywords: art design style; Chinese interior style; modern society

\begin{abstract}
With the rapid development of the economy, the continuous improvement of the industrial and technological level, the modern and post-modernist design style architecture is booming, and the interior design has ushered in a high-speed development opportunity. However, in today's globalization, the rapid development of large-scale industrial production methods and information science and technology, including people's value orientation, has gradually separated us from the traditional ethnic regional space. The interior design styles of different historical eras are in uniform standard commodity production. As a result, the design of different indoor spaces tends to be the same, the characteristics of regional culture are gradually declining, and the repetition and imitation of interior design is gradually formed. The natural ecological environment is deliberately destroyed and demanded, and the extinction and disappearance of the earth species are given to the present earth. Ecology has created an irreversible ecological status quo. Since China's reform and opening-up, driven by the market economy, the influx and enlightenment of the international wave has made China's interior design develop rapidly. However, because there is no theoretical characteristic of interior design style with Chinese characteristics as a guide, many designers blindly Following the international trend, pursuing the European style, passive design under the influence of people's values, in a simple form to cover the life value of the architectural interior design itself, thus forgetting the characteristics of its own national traditional style. Therefore, Chinese interior design will develop and progress in what direction and trend, and domestic designers are still confused and groping.
\end{abstract}

\section{Introduction}

The establishment of New China and the rapid economic development after the reform and opening up have provided sufficient conditions for the formation and development of modern interior design in China. In addition, different design thoughts have poured into China, let us first appreciate the characteristics of foreign design styles. However, because the development of interior design in China is closely related to politics, economy, science and technology, culture, geography and people's lifestyle, Chinese people's perception of interior design style has made great difference. The direct result is that interior design style is in China. The development has shown a certain degree of continuity and staged development. The formation of style shows a certain value orientation, which is the embodiment of the common development of human and natural environment. However, in the vast living environment of the world, there are different countries, nations and regions, and there are obvious differences between them, which makes the difference in design ideas between them. With the recognition of foreign design styles, the eclectic expression techniques characterized by mashup, stacking and imitation began to form in China. Under the influence of people's value orientation, designers gradually abandoned the pursuit of gorgeous expressions. Its own ethnic regional culture lacks innovation and individuality. Therefore, in many families' interior design, the phenomenon of style mixing and uniformity has arisen. The reason is that the interior design industry in China is not standardized, blindly pursuing the characteristics of foreign design styles, and the interior design styles are mixed and other factors. In this form, it also affects the development of interior design in China, and it also affects people's demand for indoor living environment space. 


\section{Comparative Study on the Characteristics of Modern Interior Design Style}

Modernist design style and postmodernism design style are produced in different era backgrounds, and are also produced and developed under different industrialization, technological and human values. Therefore, the characteristics between them are obviously different. Although many experts and scholars believe that the characteristics of postmodernist design style are the summarization and innovation of past historical design trends, they have to acknowledge the obvious conflicts and oppositions between postmodernism and modernism. In the process of social development in the same century, the two design styles, their development significance and role are undoubted, their influence on the later style design is also far-reaching, and is also used in the current social interior design. The differences between the two styles are mainly in the following aspects.

The two different design styles of indoor space use have obvious opposites in their spatial performance characteristics. The former emphasizes the practicality and functionality of space, discards the extraneous and complicated things, and emphasizes the transparency and openness of indoor space. The arrangement of the space has lower requirements for aesthetics; while the latter, under the premise of perfecting the functionality, according to the individual's preferences and needs, the space is divided and separated by personality, which is formed in the indoor space. Spatial partition of personality. It not only meets people's material needs, but also pursues people's spiritual needs, making the interior space environment design cumbersome and exquisite, with clear divisions and unique personality and taste.

Different generations of indoor space furnishings, social productivity, technology level, product model are also different, and the prerequisites for social progress and development are the same. The two design styles have different performance characteristics in the interior space decoration display: the former emphasizes the simple interior style, emphasizes the simple and meticulous interior interface and furnishings, removes unnecessary and redundant items, and resists the cumbersome decoration. The space is unified in the overall shape; the latter pursues romance, nature and elegance for the interior space decoration, and mixes and superimposes with a diversified indoor space environment to resist a single furnishings, which is cumbersome and complicated for the interior interface and furnishings. And contradictions to meet people's aesthetic needs for space, and fully reflect people's personality and innovation.

Different modernist design styles for interior space decoration use a single color in the interior space decoration, simple space shape, abandon the extra decoration means, abandon the decorations to achieve the functional indoor space environment; and postmodern The design style of the interior mixes the decorative features of different eras in the interior decoration, and uses the colorful and cumbersome decorations to create a space environment with unique and innovative features.

\section{Research on the Orientation of People's Values in Interior Design Style}

The term value orientation is the product of philosophical thinking and has a profound philosophical dialectical thinking. It refers to the different social, things, contradictions and communicative relations that people touch and face on the basis of their own values in a people-centered society. The basic value orientation and position held by the parties and show a certain tendency to the material form. Value orientation is a selective quality produced in people's social actions, social practices and ideological activities, which shows its special role in selecting, controlling and locating value. Therefore, in the process of historical evolution, the development of spiritual, material and cultural directly depends on the correct guidance of value orientation. As a way of choosing human instinct, value orientation changes with the progress of social age in the process of development. As the change of cultural thoughts changes constantly, with the development of the productivity of science and technology industry constantly changing, it is right. The choice of things in the evolutionary process is the central part of people's personality structure, and is the directional thinking mode of attitude, guidance and adjustment in the selection process. In daily life and work, people have different judgments and choices for the material form of various 
things as guidance and orientation. In psychology, the definition of values is defined as the overall idea of guiding people's actions and judgments in different work environments; Simon, a famous psychologist who won the Nobel Prize in Economics, believes that there are two preconditions for decision-making - value Premise and factual premise. From these guidelines, it is fully demonstrated that the value orientation directly affects people's daily life and production behavior.

People's values are embodied in their own needs for the material environment. Society is developing, and how society develops is not reflected in values. However, how society can develop faster and better is closely related to values. The traditional view of social development ignores the philosophical system of values, focusing only on industrial and social productivity. This is unscientific and incorrect. In the era of rapid progress, people strive to adapt to the material and spiritual products brought about by the times, and at the same time change the orientation of people's orientation in different periods. These factors are full of the content of philosophical dialectics, which makes us more vague and unclear in the orientation analysis. In many cases, people have the concept of values in the process of choice, and ask what kind of products or articles they have. Value, how to distinguish its value, how to use its value, etc., make people become more and more confused about these factors, more and more unclear, rapid social development speed, also makes us lost in value orientation The road. Therefore, the mutual influence between the new material produced under the rapid development of society and people's value orientation is an intrinsic manifestation of the development of modern industrialization and scientific and technological social civilization. But modern society and the values it embody affect the development and progress of people's value orientation. In modern society, the economic development is the ultimate goal and consequence, which in itself reflects its values. In the composition of the people-oriented social group, the natural environment and materials other than the owner are the objects that are provided for life, use and possession. People also identify and confirm the value orientation in the continuous exploration of its usability and usefulness. Therefore, in the era of constant change, people's value orientation will also change and evolve, creating people's views and thoughts on valuable goods in different eras, thus promoting the evolution of things and promoting the development of productive forces. Promoted the progress of the scientific and technological society. In general, people's choice of value orientation has greatly promoted the development and progress of the times.

The characteristics of interior design style formed in any era are influenced by the cultural, economic, political, and geographical factors of the society at that time, and the influence of the orientation development of people's values on the development of interior design style cannot be ignored of Since ancient times, many people's value orientation has been fully reflected in consumption. The pursuit of luxury, bright environmental appearance has also caused the value orientation to lose its direction, leading to the uncontrolled development of nature and the social environment. The heavy pollution pressure has caused hidden dangers to people's daily life, which has distorted the direction of human-centered interior design style, which casts a shadow on people's comfortable living space and seriously threatens social life. Sustainability. In the process of social progress and development in our country, especially after the reform and opening up, people's living standards have been increasing. People have gradually got money. They have the living space environment that suits them and bought their favorite items, but this is the modern development. Reflect it? Is this the scene of the prosperity of interior design? Under the background of the progress of society and the gradual improvement of people's living conditions, interior design presents a prosperous scene under the control of values, that is, under the influence of people's value orientation, the popularity of European style, its regional ethnic characteristics. The departure of the two has produced the emergence of the imitation of European style of interior design, and also reflects the narrowness of values in people's minds and the imperfection of their own national consciousness.

\section{Conclusion}

The characteristics of interior design style formed from ancient times to present provide a 
profound source of development for the development of modern interior design. Through the theoretical study of the characteristics of interior design formed during the historical development process, it is the theory of exploring the future development trend of interior design. Foundation and development basis. This thesis conducts detailed research and analysis on the origin and development theory of interior design style. The development characteristics of traditional interior design style are analyzed and discussed through actual cases, and the development characteristics of modern interior design style are compared in detail. Integrate the development of society and the orientation of people's values into the development process of interior design style, and enumerate the current development status of interior design, study the environmental protection concept of harmonious development of people and ecology, and provide guidance for the future development direction of the world and Chinese interior design style. Sexual advice.

\section{References}

[1] Li Hongli, the process of architectural design [J], Shanxi Architecture, 2004 (7): 9-10

[2] Duan Ping, interior design status and development trend [J], Hunan Packaging, 2012 (2): 44-46

[3] Zheng Shiling, Chinese cities and buildings under the influence of globalization [J], Journal of Architecture, 2003 (2) 7

[4] Wang Qiong, on the contemporary transformation of retro style in interior design [J], Science and Technology Information, 2007 (30) 453 